\title{
Silver (I)-coordinated bis(trimethoxysilylpropyl)amine Polycondensate for Adsorptive Removal of lodide from Aqueous Solutions
}

\author{
ZHANG Huifang $^{1, \text { a }}$, WU Zhijian ${ }^{1, \mathrm{~b}}$, YE Xiushen ${ }^{1, \mathrm{c}}$, WU Chengyou ${ }^{2, \mathrm{~d}}$ \\ and LI Quan ${ }^{1, \mathrm{e} *}$ \\ ${ }^{1}$ Qinghai Institute of Salt Lakes, Chinese Academy of Sciences, Xining 810008, China \\ ${ }^{2}$ Qinghai University, Xining 810016, China \\ azhf233007@126.com, ${ }^{\mathrm{b}} \mathrm{zjwu} @$ isl.ac.cn, ${ }^{\mathrm{c}} 78043139 @$ qq.com, ${ }^{\mathrm{d}}$ wuchengyou86@163.com, \\ eliquan@isl.ac.cn
}

\begin{abstract}
Silver-coordinated bis(trimethoxysilylpropyl)amine polycondensate (TSPA- $\mathrm{AgNO}_{3}$ ) was prepared and used to adsorb iodide ions in aqueous solutions. Batch adsorption studies were performed to investigate the effects of $\mathrm{pH}$, temperature and coexisting $\mathrm{NaCl}$ on adsorption behavior. The results show that TSPA- $\mathrm{AgNO}_{3}$ is easy to prepare and remarkably efficient in adsorbing iodide in water, especially in acidic solutions. Furthermore, increased temperature accelerated the adsorption, while coexisting $\mathrm{NaCl}$ inhibited the adsorption. TSPA- $\mathrm{AgNO}_{3}$ also proved to be chemically stable in simulated environmental situations, which reveals a promising potential for applying this method to the disposal of radioactive iodide in environment water.
\end{abstract}

Keywords: Bis(trimethoxysilylpropyl)amine; Iodide; Adsorption; Coordination

\section{Introduction}

Radioactive iodine is released into the environment during the course of normal nuclear power plant operation and by nuclear accidents such as that in 2011 at Fukushima, Japan. Beyond that, radioactive iodide is increasingly used in biological experiments, medical treatments and disease diagnostics, creating radioactive iodide waste that is collected and stored $[1,2]$. Radioiodide has well-known risks. It can be readily accumulated in the body, especially in the thyroid, where it causes a significant health hazard. Different substances have been discussed as potential adsorbents to aid in removing radioactive iodide from experimental liquid waste and water contaminated by nuclear waste. For example, one study placed pure metallic silver membranes in a screwable holder for the removal of free radioiodide from I-radiopharmaceuticals [1], but the difficult preparation process may constrain this method's application in radioiodide separation from radioactive waste. Anion exchange cellulose paper membranes, which can remove radioactive iodide and effectively

*Corresponding author: liquan@isl.ac.cn 
store it until it can be discarded, usually comprise dimethylaminoethyl groups as well as trimethylhydroxypropylammonium [2,3]. Iodide ions selectively permeate throughout the anion exchange paper membrane, forming ion pairs with cations in the solution. However, the anion exchange paper membrane method is not applicable to the problem of immobilizing radioactive iodide released into the environment, although it holds promising potential for reducing the volume of experimental waste.

Organophilic bentonite, zeolite, surfactant-modified zeolite and chemically pretreated clinoptilolite have been investigated for removing radioiodide from simulated environmental water [4-7]. A group of minerals including $11 \AA$ tobermorite, attapulgite, allophone, clinoptilolite, ferrihydrite, goethite, pyrite and marcasite were assessed with respect to iodide retention in high-level radioactive waste (HLRW) repositories. Of these, organic surfactant modified bentonite (by hexadecylpridinium chloride, quaternary alkylmmonium salts, distearyldimethyl ammonium chloride, and others) was found to be the most promising candidate material because of high iodide adsorption capacity as well as selectivity of organoclays [8]. However, the required thermal stability of organoclays demands further discussion. Meanwhile, silver-impregnated porous solid adsorbents have proven to be quite effective in removing and sequestering radioactive iodine in the form of silver-iodine compounds [9-12]. Previous works have investigated porous solid materials such as styrene-divinylbenzene copolymer, silica gel, zeolite and active carbon. However, silver-impregnated porous solid adsorbents continue to present shortcomings such as a complex preparation process and chemical instability and uniformity, probably due to the lack of an especially strong affinity between silver ions and the porous material.

Bis(trimethoxysilylpropyl)amine (TSPA) is a silane coupling agent with applications as a controlled release carrier for water-soluble drugs; a surface treatment agent for enhancing corrosion resistance in steel; an adhesion promoter; and an optical, dielectric and protective coating $[13,14]$. TSPA gels quickly in water and forms xerogel with good mechanical strength after drying. Taking advantage of these properties as well as the $-\mathrm{NH}-$ groups in TSPA, we prepared silver-coordinated bis(trimethoxysilylpropyl)amine polycondensate (hereafter referred to as TSPA- $\mathrm{AgNO}_{3}$ ) for adsorbing iodide from aqueous solutions. We investigated the adsorption behavior of TSPA- $\mathrm{AgNO}_{3}$ towards iodide, and we studied the effects of different parameters including solution $\mathrm{pH}$, temperature and coexisting $\mathrm{NaCl}$ on the adsorption process in order to identify the optimal conditions for the adsorptive removal of iodide from aqueous solutions.

\section{Experimental Details}

\subsection{Materials.}

All reagents except TSPA were of analytical grade and used as received from Shanghai Boer Chemical Reagent Co. Ltd., China, and TSPA was purchased from Nanjing Capatue Chemical Co., Ltd., China, without further purification. This study used stable iodide (I-127) as a surrogate for radioactive iodide (I-129).

\subsection{Preparation of TSPA-AgNO3.}

We added $1.7 \mathrm{~g}(0.01 \mathrm{~mol})$ of $\mathrm{AgNO}_{3}$ into $7.5 \mathrm{~mL}(0.02 \mathrm{~mol})$ of TSPA, and soon afterwards the liquid became dark brown. Then the mixture was sealed up and shaken for 48 hours to ensure that the $\mathrm{AgNO}_{3}$ was adequately dissolved into the TSPA at ambient temperature. Afterwards, the solution was mixed into $30 \mathrm{~mL}$ of distilled water under 
magnetic stirring until gelation. After 24 hours of aging, the gel composite was dried at $40{ }^{\circ} \mathrm{C}$ in an oven. It was ground up and repeatedly washed with distilled water until the washing liquid tested negative for $\mathrm{AgNO}_{3}$ due to precipitation of $\mathrm{AgCl}$. It was then dried again. Finally, the TSPA- $\mathrm{AgNO}_{3}$ was pulverized using a mortar and pestle to isolate 20-60 mesh sized particles, which were stored in a brown sample bottle until the adsorption experiments.

\subsection{Analytical methods.}

Ultraviolet visible spectrophotometry (TU-1810, Beijing Purkinje General Instrument Co., Ltd.) determined the iodide ion concentration in the aqueous solution at the absorption wavelength of iodide aqueous solutions $(226 \mathrm{~nm} ; 220.0$ and $231.5 \mathrm{~nm})[15,16]$. The $\mathrm{pH}$ of point of zero charge $\left(\mathrm{pH}_{\mathrm{PZC}}\right)$ for $\mathrm{TSPA}-\mathrm{AgNO}_{3}$ was detected using the $\mathrm{pH}$ equilibrium method as described in the reference work [17]. Solution $\mathrm{pH}$ was measured with a Sartorius PB-10 pH meter. Fourier Transform Infrared Spectrometry (FTIR) spectra of the TSPA gel and TSPA- $\mathrm{AnNO}_{3}$ were obtained to analyze the coordination between silver ions and - NHgroups in TSPA. In addition, X-ray diffraction (XRD) and scanning electron microscopy (SEM) analyses were conducted to characterize the $\mathrm{TSPA}^{-} \mathrm{AgNO}_{3}$ before and after adsorption.

\subsection{Batch adsorption experiments.}

Batch adsorption experiments were conducted as follows. Approximately $0.1 \mathrm{~g}$ of TSPA- $\mathrm{AgNO}_{3}$ was placed into $100 \mathrm{~mL}$ iodide solutions at different initial $\mathrm{pH}$ levels $(1,3,5$, $7,9,11)$, temperatures $\left(25,35,45,55^{\circ} \mathrm{C}\right)$ and coexisting $\mathrm{NaCl}$ concentrations $(0,1,2,3,45$ $\mathrm{mol} / \mathrm{L}$ ). The solutions were in a water bath with a constant shaking speed of $170 \mathrm{rpm}$. Solution $\mathrm{pH}$ was adjusted using $\mathrm{HCl}$ and $\mathrm{NaOH}$ solutions. The adsorption quantity of iodide onto TSPA- $\mathrm{AgNO}_{3}$ is calculated using Eq. 1:

$$
q_{t}=\frac{V\left(C_{0}-C_{t}\right)}{m} .
$$

In Eq. $1, q_{t}$ is the adsorption quantity of iodide onto the adsorbent $(\mathrm{mmol} / \mathrm{g})$ at time $t, V$ is the volume of the solution (L), and $m$ is the mass of the adsorbent $(\mathrm{g}) . C_{0}$ and $C_{t}$ represent iodide concentrations in the solution $(\mathrm{mmol} / \mathrm{L})$ at initial and time $t$, respectively. When equilibrium iodide concentration $C_{e}$ is substituted for $C_{t}$, Formula 1 yields equilibrium adsorption quantity, $q_{e}(\mathrm{mmol} / \mathrm{g})$.

\section{Results and Discussion}

\subsection{Preparation of TSPA-AgNO3 composite adsorbent.}

One secondary amine group lies in the middle with a trimethoxysilylpropyl group on either end of TSPA. In light of previous research on complexation between $\mathrm{Ag}^{+}$and amino-containing compounds [18-21], we inferred that $\mathrm{AgNO}_{3}$ could dissolve into TSPA. Furthermore, the FTIR analyses of TSPA gel and TSPA-AgNO ${ }_{3}$ gel displayed in Fig. 1 also evidence the formation of the $\mathrm{Ag}^{+}$- amine complex. Various changes occurred with the transformation of TSPA gel to TSPA- $\mathrm{AgNO}_{3}$ gel, including the following: (1) Similar to the results of previous work [22], N-H stretching vibration and intermolecular hydrogen bonding stretching vibration at $3500-3100 \mathrm{~cm}^{-1}$ split, N-H stretching vibration receded to $3240 \mathrm{~cm}^{-1}$, and N-H bending vibration at $1545 \mathrm{~cm}^{-1}$ disappeared; (2) $\mathrm{C}-\mathrm{H}$ stretching vibration at 2858 
$\mathrm{cm}^{-1}$ strengthened; and (3) A characteristic absorption peak of $\mathrm{NO}_{3}{ }^{-}$at $1385 \mathrm{~cm}^{-1}$ appeared. These results show the weakening of $\mathrm{N}-\mathrm{H}$ bonds and the slight strengthening of $\mathrm{C}-\mathrm{H}$ bonds in TSPA- $\mathrm{AgNO}_{3}$ gel compared to TSPA gel, confirming the formation of complexing action between $\mathrm{Ag}^{+}$and $-\mathrm{NH}-$ groups.

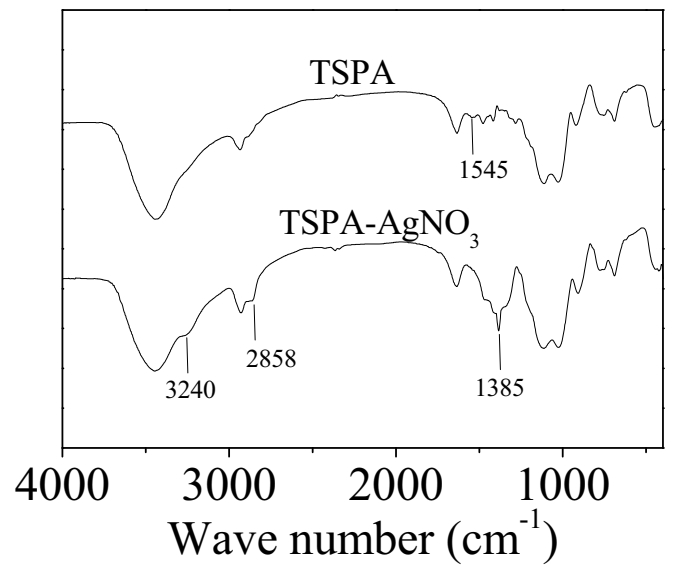

Fig. 1 FTIR spectra of TSPA and TSPA- $\mathrm{AgNO}_{3}$

\subsection{Effect of solution initial pH.}

Fig. 2A displays the effect the solution $\mathrm{pH}$ exerts on the adsorption of iodide ions onto TSPA- $\mathrm{AgNO}_{3}$. The solution $\mathrm{pH}$ remarkably affects both the adsorption rate and the adsorption quantity. The adsorption rate and quantity decline sharply as $\mathrm{pH}$ increases from 1 to 11 . When $\mathrm{pH}$ is between 1 and 3, the equilibrium adsorption quantity reaches about 0.8 $\mathrm{mmol} / \mathrm{g}$, but this figure is $0.4 \mathrm{mmol} / \mathrm{g}$ when $\mathrm{pH}$ is between 5 and 9 , and it is only $0.1 \mathrm{mmol} / \mathrm{g}$ when $\mathrm{pH}$ is 11 . Furthermore, according to the slope of the adsorption curve, the average adsorption rate in the first 24 hours for strong acidic solutions was higher than that in strong basic solutions. The $\mathrm{pH}_{\mathrm{PZC}}$ of TSPA- $\mathrm{AgNO}_{3}$ is 9.5 , and TSPA- $\mathrm{AgNO}_{3}$ consumes $\mathrm{H}^{+}$in solution and changes the solution $\mathrm{pH}$ from 5-9 to 8-9.5. Therefore, when the solution $\mathrm{pH}$ is 11 , the surface of TSPA- $\mathrm{AgNO}_{3}$ is negatively charged and repels I; in contrast, a positively charged surface and plentiful $\mathrm{H}^{+}$in solution is likely to promote the adsorption reaction between iodide and TSPA- $\mathrm{AgNO}_{3}$ when $\mathrm{pH}$ is between 1 and 3 . Therefore, the $\mathrm{pH}$ range of 1 to 3 should be considered optimal for the adsorption of iodide onto TSPA- $\mathrm{AgNO}_{3}$.

\subsection{Effect of temperature.}

Our study also observed the effect of temperature on adsorption in acidic solutions $\left(\mathrm{pH}_{0}\right.$ $=3$ ). As Fig. $2 \mathrm{~B}$ shows, the average adsorption rate in the first 24 hours increases as the temperature rises from $25{ }^{\circ} \mathrm{C}$ to $55{ }^{\circ} \mathrm{C}$. However, the adsorption quantity over 144 hours, which is considered to approximate the thermodynamic equilibrium adsorption quantity, declines from $0.82 \mathrm{mmol} / \mathrm{g}$ at $25{ }^{\circ} \mathrm{C}$ to $0.66 \mathrm{mmol} / \mathrm{g}$ at $55^{\circ} \mathrm{C}$. It appears that raising the temperature promotes the diffusion of ions and molecules in aqueous solutions, and consequently accelerates adsorption reactions. The difference between approximate equilibrium adsorption quantities at different temperatures probably results from the fact that adsorption products in acidic solutions, in this case silver iodide, tend to be more unstable at higher temperatures. Given the efficiency of the batch adsorption operation, we suggest that temperature and adsorption time be regulated at $25-35^{\circ} \mathrm{C}$ and 72 hours, respectively. 


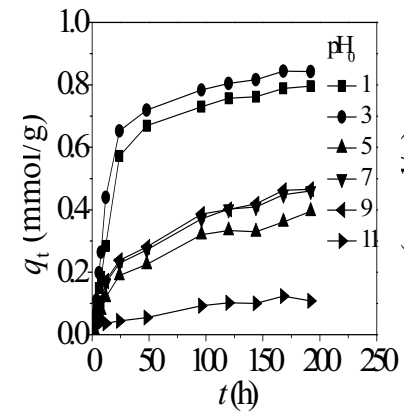

A

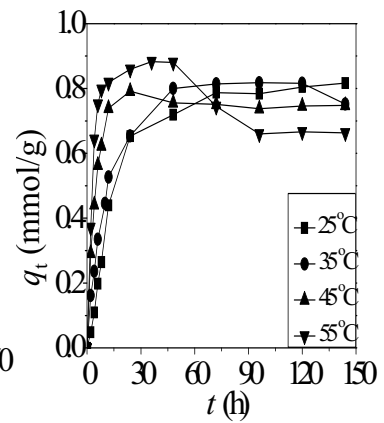

B

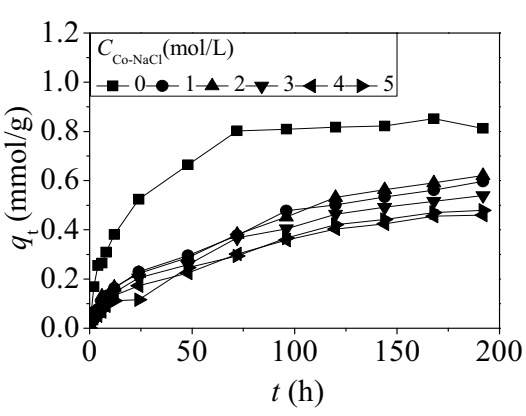

$\mathrm{C}$

Fig. 2 Effect of initial solution pH (A), temperature (B) and coexisting $\mathrm{NaCl}(\mathrm{C})$ on the adsorption of iodide onto TSPA-AgNO3

\subsection{Effect of coexisting $\mathrm{NaCl}$.}

In most actual systems, high $\mathrm{Cl}^{-}$content is a main interfering factor for adsorbing and separating iodide because of their similar properties. Therefore, the adsorption experiments with different concentrations of coexisting $\mathrm{NaCl}(0,1,2,3,4,5 \mathrm{~mol} / \mathrm{L})$ were conducted at 25 ${ }^{\circ} \mathrm{C}$ in acidic solutions $(\mathrm{pH}=3)$. The results displayed in Fig. $2 \mathrm{C}$ indicate that coexisting $\mathrm{NaCl}$ inhibits the adsorption of iodide onto TSPA- $\mathrm{AgNO}_{3}$, results that are in agreement with the previous related work [7]. The quantity adsorbed over 72 hours decreases sharply from 0.8 $\mathrm{mmol} / \mathrm{g}$ to $0.3 \mathrm{mmol} / \mathrm{g}$ when the concentration of coexisting $\mathrm{NaCl}$ increases from $0 \mathrm{~mol} / \mathrm{L}$ to $5 \mathrm{~mol} / \mathrm{L}$. It is possible that a higher adsorption quantity could be achieved if the time were extended; For example, $0.4 \mathrm{mmol} / \mathrm{g}$ might be adsorbed in a $5 \mathrm{~mol} / \mathrm{L}$ coexisting $\mathrm{NaCl}$ solution after 144 hours.

\subsection{Adsorption dynamic and thermodynamic models.}

The experimental kinetic and equilibrium data at $25^{\circ} \mathrm{C}$ shown in Figures 5, 6 and 7 were analyzed using the kinetic and thermodynamic models (Formulas 2-5) proposed previously [23-25].

Pseudo-first-order model: $q_{t}=q_{e}-\frac{q_{e}}{e^{k_{L} t}}$

$$
\text { Pseudo-second-order model: } q_{t}=\frac{k_{H} q_{e}{ }^{2} t}{1+k_{H} q_{e} t}
$$

Langmuir isotherm: $\frac{C_{e}}{q_{e}}=\frac{1}{K_{L} Q_{m}}+\frac{C_{e}}{Q_{m}}$

Freundlich isotherm: $\ln q_{e}=\ln K_{F}+\frac{1}{n} \ln C_{e}$

In these equations, $q_{t}$ and $q_{e}$ are the adsorption quantities at time $t$ and at equilibrium, respectively; $k_{L}$ and $k_{H}$ are the adsorption rate constants for the pseudo-first-order and pseudo-second-order models, respectively; $Q_{\mathrm{m}}$ is the adsorption capacity; $K_{L}$ is the Langmuir coefficient; $1 / n$ is the heterogeneity factor of the adsorbent; and $K_{F}$ is the Freundlich equation constant. 


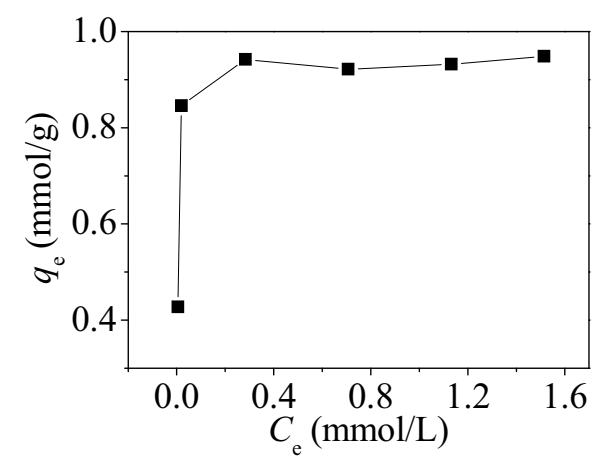

Fig. 3 Adsorption isotherm at $25{ }^{\circ} \mathrm{C}$ in acidic solution

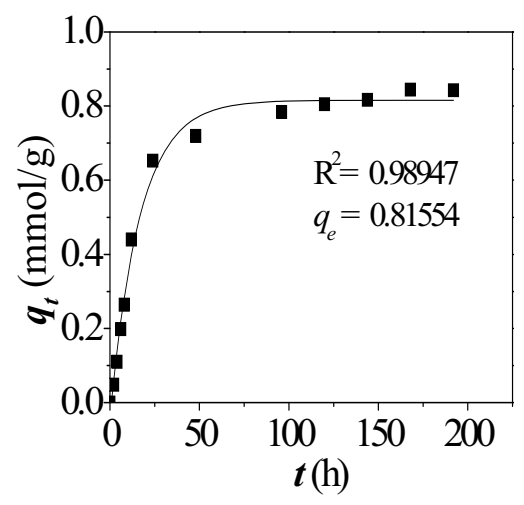

(a)

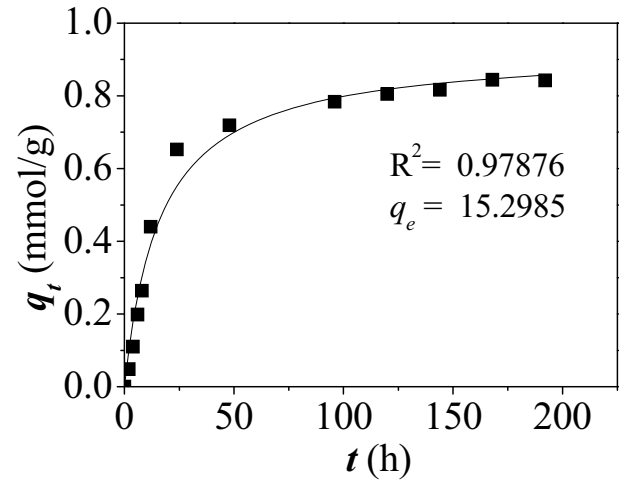

(b)

Fig. 4 Kinetic models for the adsorption of iodide onto TSPA-AgNO3 at $25^{\circ} \mathrm{C}$, (a) pseudo-first-order model; (b) pseudo-second-order model

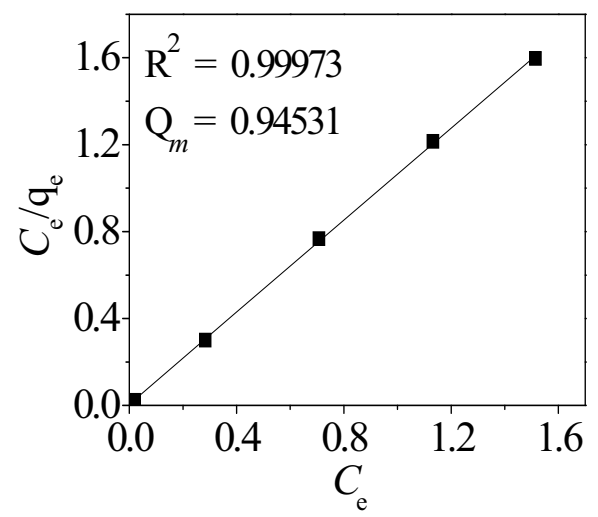

(a)

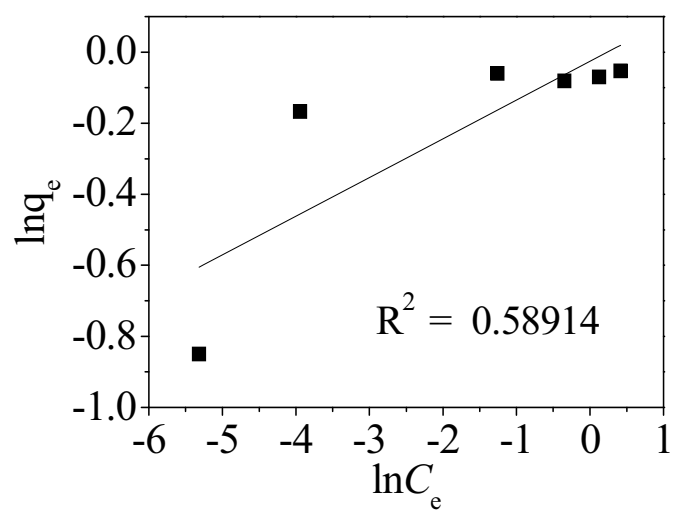

(b)

Fig. 5 Isotherm models for the adsorption of iodide onto TSPA-AgNO3 at $25^{\circ} \mathrm{C}$, (a) Langmuir model;

(b) Freundlich model

Fig. 4 and Fig. 5 show the fitting results for the kinetic and thermodynamic models. Based on the correlation coefficients and the degree of closeness between the calculated equilibrium adsorption quantities $(0.8 \mathrm{mmol} / \mathrm{g}$ for pseudo-first-order and $15 \mathrm{mmol} / \mathrm{g}$ for 
pseudo-second-order) and the experimental equilibrium adsorption quantity $(0.8 \mathrm{mmol} / \mathrm{g})$, the pseudo-first-order dynamic model and Langmuir isotherm model appear to describe and predict accurately the adsorption behaviors of iodide onto TSPA- $\mathrm{AgNO}_{3}$ in strong acidic solutions $(\mathrm{pH}=1-3)$. The pseudo-first-order dynamic model lumps together all steps of the adsorption process, including external diffusion, internal diffusion, and adsorption [26]. Therefore, the overall adsorption process of iodide onto TSPA- $\mathrm{AgNO}_{3}$ appears similar to a first-order reaction. The Langmuir model assumes that the solute is adsorbed onto a finite number of binding sites with the same energy levels found on a homogenous surface, and that the adsorption occurs on a monolayer surface with no interaction between adsorbed molecules [27].
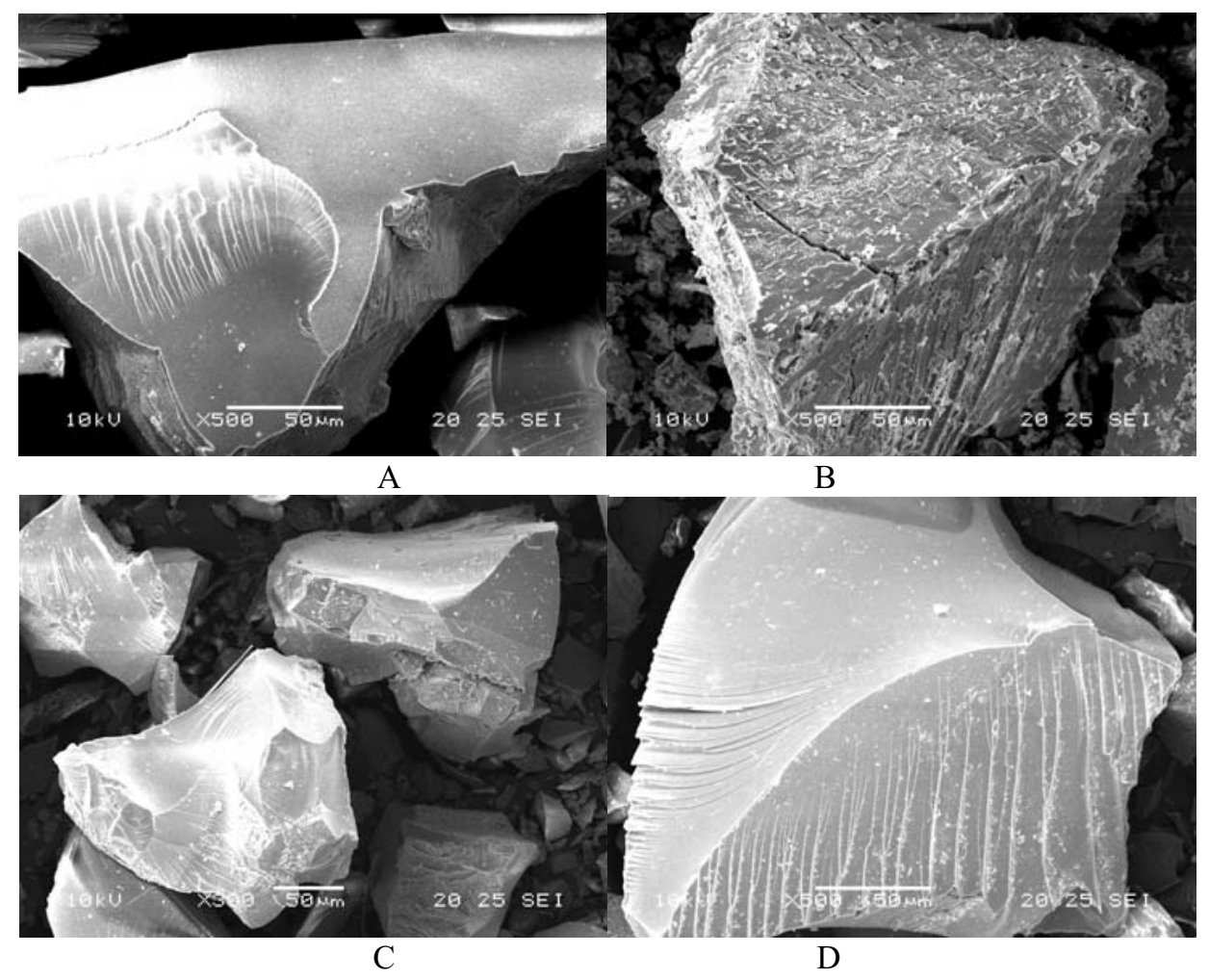

Fig. 6 SEM images of TSPA-AgNO3 before (A) and after adsorption ( $\mathrm{pH}=3$ were $\mathrm{B}$; $\mathrm{pH}=7$ were $\mathrm{C}$; $\mathrm{pH}=11$ were $\mathrm{D})$ 




Fig. 7 XRD of TSPA-AgNO3 before (a) and after adsorption ( $\mathrm{pH}=3$ was $\mathrm{b} ; \mathrm{pH}=7$ was $\mathrm{c} ; \mathrm{pH}=11$ was d)

\section{Adsorption mechanism.}

SEM and XRD analysis were performed for TSPA- $\mathrm{AgNO}_{3}$ before and after adsorption to explore further the adsorption behavior of iodide ions. Figures 8 and 9 display SEM and XRD analysis results, which can be summarized as follows: (1) TSPA- $\mathrm{AgNO}_{3}$ is uniform, compact and amorphous before adsorption, and no crystal $\mathrm{AgNO}_{3}$ exists in TSPA-AgNO adsorbent, further illustrating the formation of $\mathrm{Ag}^{+}$- amine coordination. (2) Many silver iodide and silver chloride agglomerates occur over the matrix after adsorption in strong acidic solutions adjusted using $\mathrm{HCl}$. Furthermore, nitrate ions infiltrate into the solution when iodide ions are adsorbed onto TSPA- $\mathrm{AgNO}_{3}$.

Based on the effects of solution $\mathrm{pH}$ and coexisting $\mathrm{NaCl}$, as well as the analysis results listed above, we conclude that the adsorption of iodide ions onto TSPA- $\mathrm{AgNO}_{3}$ involves two processes: (1) $\mathrm{NO}_{3}{ }^{-}$, the counterbalance ion of the $\mathrm{Ag}^{+}$- amine coordination complex, is exchanged with anions such as $\mathrm{I}^{-}, \mathrm{Cl}^{-}$, or $\mathrm{OH}^{-}$in solution. (2) In strong acidic solutions $(\mathrm{pH}=1-3)$, the interaction of the coexisting $\mathrm{H}^{+}$and the secondary amine group in the matrix results in the weakening of the $\mathrm{Ag}^{+}$- amine coordination, consequently promoting the reaction between $\mathrm{Ag}^{+}$and the precipitating agent like $\mathrm{I}^{-}$or $\mathrm{Cl}^{-}$that diffuses into the gel matrix to form $\mathrm{AgI}$ or $\mathrm{AgCl}$. Therefore, the immobilization of iodide using TSPA- $\mathrm{AgNO}_{3}$ in acidic aqueous solutions is closely related to the precipitation of silver iodide on the surface of TSPA- $\mathrm{AgNO}_{3}$ (see Eq. 6). In neutral or slightly alkaline solutions, $\mathrm{NO}_{3}{ }^{-}$is exchanged with $\mathrm{I}^{-}$ as the counterbalance ion of the $\mathrm{Ag}^{+}$- amine coordination complex (Eq. 7).

$$
\begin{aligned}
& {[\text { TSPA-Ag }]^{+} \mathrm{NO}_{3}{ }^{-}+\mathrm{I}^{-} \stackrel{\mathrm{H}^{+}}{=} \text {TSPA-AgI }+\mathrm{NO}_{3}{ }^{-}} \\
& {[\text {TSPA-Ag }]^{+} \mathrm{NO}_{3}{ }^{-}+\mathrm{I}^{-}=[\text {TSPA-Ag }]^{+} \mathrm{I}^{-}+\mathrm{NO}_{3}{ }^{-}}
\end{aligned}
$$

\section{Summary}

Silver-coordinated bis(trimethoxysilylpropyl)amine polycondensate (TSPA-AgNO 3 ) was prepared and used to adsorb iodide ions in aqueous solutions. The main conclusions of these experiments are as follows: 
(1) Silver nitrate can dissolve into TSPA, forming a uniform dark brown TSPA-AgNO complex.

(2) TSPA- $\mathrm{AgNO}_{3}$ is easy to prepare and remarkably efficient in adsorbing iodide ions in water, especially in acidic solutions. The adsorption capacity of iodide ions onto TSPA- $\mathrm{AgNO}_{3}$ is nearly $0.9 \mathrm{mmol} / \mathrm{g}$ when the solution $\mathrm{pH}$ is between 1 and 3 , and it declines to $0.1 \mathrm{mmol} / \mathrm{g}$ as the solution $\mathrm{pH}$ increases to 11 . Furthermore, increased temperature can accelerate the adsorption rate. However, coexisting $\mathrm{NaCl}$ can inhibit adsorption, and the quantity adsorbed over 72 hours decreases from $0.8 \mathrm{mmol} / \mathrm{g}$ to $0.3 \mathrm{mmol} / \mathrm{g}$ when the concentration of coexisting $\mathrm{NaCl}$ increases from $0 \mathrm{~mol} / \mathrm{L}$ to $5 \mathrm{~mol} / \mathrm{L}$. The pseudo-first-order dynamic model and Langmuir isotherm model well describe and predict the adsorption behaviors of iodide onto TSPA- $\mathrm{ANO}_{3}$ in acidic solutions $(\mathrm{pH}=1-3)$.

\section{Acknowledgements}

This work was supported by the National Natural Science Foundations of China (Grant No. 21401209 and No. U1407104), Natural Science Foundations of Qinghai Province (Grant No. 2015-ZJ-947Q and No. 2015-ZJ-933Q), and Application Research Foundations of Qinghai Province (Grant No. 2013-Z-706).

\section{References}

1. L.H. Eersels, G.J. Custers, G.J. Ensing, D.M. Herscheid, A simple and efficient method to remove free radioiodide from I-radiopharmaceuticals, Eur J Nucl Med 22 (1995) $1185-1186$.

2. H. Inoue, M. Kagoshima, Removal of ${ }^{125}$ I from radioactive experimental waste with an anion exchange paper membrane, Appl Radiat Isotopes 52 (2000)1407-1412.

3. H. Inoue, Effects of co-ions on transport of iodide ions through a non-conventional anion exchange paper membrane, J Membrane Sci 228 (2004)209-215.

4. J. Bors, A. Gorny, S. Dultz, Sorption characteristics of radioiodide on organophilic bentonite, Radiochim Acta 78 (1997)117-121.

5. H. Faghihian, M.G. Maraghheh, A. Malekpour, Adsorption of radioactive iodide by natural zeolites, J Radioanal Nucl Ch 254 (2002)545-550.

6. H. Faghihian, A. Malekpour, M.G. Maragheh, Removal of radioactive iodide by surfactant-modified zeolites, Adsorpt Sci Technol 21 (2003) 373-381.

7. E. Cheielewská-Horvathová, J. Lesný, Iodide adsorption on the surface of chemically pretreated clinoptilolite, J Nucl Ch Lett 200 (1995) 351-363.

8. S. Kaufhold, M. Pohlmann-Lortz, R. Dohrmann, About the possible upgrade of bentonite with respect to iodide retention capacity, Nüesch R Appl Clay Sci 35 (2007) 39-46.

9. K.Takenshita, Y.Takashima, S.Matsumoto, S.I. Inami, Effect of grain size of $\mathrm{AgNO}_{3}$ loaded in porous material on adsorption of $\mathrm{CH}_{3} \mathrm{I}$, J Nucl Sci Technol 32 (1995) 941-943

10. H. Mineo, M. Gotoh, M. Iizuka, S. Fujisaki, G. Uchiyama, A simple model predicting iodine profile in a packed bed of silica-gel impregnated with silver nitrate, J Nucl Sci Technol 39 (2002) 241-247.

11. J.S. Hoskins, T. Karanfil, S.M. Serliz, Removal and sequestration of iodide using silver-impregnated activated carbon, Environ Sci Technol 36 (2002)784-78.

12. T. Karanfil, E.C. Moro, S.M. Serkiz, Development and testing of a silver chloride-impregnated activated carbon for aqueous removal and sequestration of iodide, Environ Technol 26 (2005)1255-1262. 
13. Y. Jiang, Z.J. Wu, L.J. You, H. Xiang, Bis(trimethyloxysilylpropyl)amine and tetraethoxysilane derived gels as effective controlled release carriers for water-soluble drugs of small molecules, Colloid Surface B 49 (2006) 55-59.

14. G.R. Pan, D.W. Schaefer, W.J. Ooij, M.S. Kent, J. Majewski, H. Yim, Morphology and water resistance of mixed silane films of bis[3-(triethyloxysilyl)propy]tetrasulfide and bis-[trimethyloxysilylpropyl]amine, Thin Solid Films 515 (2006) 2771-2780.

15. H.F. Zhang, H.N. Liu, M. Guo, X.S. Ye, Q. Li, Z.J. Wu, Rapid determination of trace iodide in solutions by UV spectrophotometry, J Anal Sci 27 (2011) 238-240 (in chinese) .

16. H.F. Zhang, T. Guo, Q. Li, X.S. Ye, Z.J. Wu, Simultaneous determination of nitrate and iodide ions in aqueous solutions by dual-wavelength spectrophotometry, Chinese J Inorg Anal Ch 1 (2011) 24-28 (in chinese).

17. S. Mustafa, B. Dilara, K. Nargis, A. Naeem, P. Shahida, Surface properties of the mixed oxides of iron and silica, Colloid and Surface A 205 (2002) 273-282.

18. P.L. Meo, F. D'Anna, M. Gruttadauria, S. Riela, R. Noto, Synthesis and characterization of new polyamino-cyclodextrin materials, Carbohyd Res 347 (2012) 32-39.

19. V. Amendola, G. Bergamaschi, M. Boiocchi, L. Fabbrizzi, N. Fusco, The solution stability of copper(I) and silver(I) complexes with $N$-heterocyclic carbenes, Dalton T 40 (2011) 8367-8376.

20. Z.F. Gesse, V.A. Isaeva, G.I. Repkin, V.A. Sharnin, Dependence of the enthalpies of formation of $\mathrm{Ag}^{+}$complexes with glycinate ion and the protonation of glycinate ion on the content of aqueous ethanol solvent, Russ J Phys Chem A 86 (2012) 59-64.

21. J. Dessingou, A. Mitra, K. Tabbasum, G.S. Baghel, C.P. Rao, Benzimidazole conjugate of 1, 1'-thiobis(2-naphthol) as switch-on fluorescence receptor for $\mathrm{Ag}^{+}$and the complex as secondary recognition ensemble toward Cys, Asp, and Glu in aqueous methanolic solution: synthesis, characterization, ion and amino acid recognition, computational studies, and microscopy features, J Org Chem 77 (2012)371-378.

22. L.D. Pollo, L.T. Duarte, M. Anacleto, A.C. Habert, C.P. Borges, Polymeric membranes containing silver salts for propylene/propane separation, Braz J Chem Eng 29 (2012) 307-314.

23. Y.S. Ho, G. McKay, Sorption of dye from aqueous solution by peat, Chem Eng J 70 (1998) 115-124.

24. I. Langmuir, The adsorption of gases on plane surfaces of glass, mica and platinum, $\mathrm{J}$ Am Chem Soc 40 (1918)1361-1368.

25. H.M.F. Freundlich, Over the adsorption in solution, J Phys Chem 63 (1959)1024-1029.

26. X.S. Ye, Z.J. Wu, W. Li, H.N. Liu, Q. Li, B.J. Qing, M. Guo, F. Ge, Rubidium and cesium ion adsorption by an ammonium molybdophosphate-calcium alginate composite adsorbent, Colloid Surface A 342 (2009) 76-83.

27. R.I. Yousef, B. El-Eswed, A.H. Al-Muhtaseb, Adsorption characteristics of natural zeolites as solid adsorbents for phenol removal from aqueous solutions: Kinetics, mechanism, and thermodynamics studies, Chem Eng J 171 (2011) 1143-1149. 